\title{
RAMON LLULL FRENTE A LA CRÍTICA ACTUAL AL DIÁLOGO INTERRELIGIOSO: EL ARTE LULIANA COMO PROPUESTA PARA UNA «FILOSOFÍA DE LAS RELIGIONES»*
}

\author{
Alexander Fidora \\ J. W. Goethe-Universität Frankfurt am Main
}

\section{RESUMEN}

En los últimos años han surgido, bajo el título de una Teología pluralista de las Religiones, varias críticas entorno a la posibilidad de un auténtico diálogo interreligioso desde la posición tradicional de la Iglesia. El presente artículo quiere demostrar cómo, a partir de la apologética luliana, pueden evitarse varias dificultades a las que apuntan los teólogos pluralistas, como por ejemplo John Hick, sin tener que abandonar por ello la pretensión de verdad universal que caracteriza a todas las religiones. A este fin, se analizaran brevemente las críticas actuales al diálogo interreligioso, presentando luego los rasgos distintivos de la apologética luliana, a saber, la duda y el filosofar, y proponiendo, para acabar, una Filosofía de las Religiones inspirada en Llull y la teología actual.

Palabras clave: Ramon Llull, John Hick, Diálogo de las Religiones, Inclusivismo, Teología pluralista de las Religiones, Filosofía de las Religiones.

\begin{abstract}
During the last few years several criticisms concerning the possibility of an authentic interreligious dialogue within the traditional doctrine of the Church have emerged under the title of a Pluralistic Theology of Religions. The present paper tries to show how many of the problems pointed at by the pluralistic theologians, as for instance John Hick, can be solved by Ramon Llull's concept of apologetics without abandoning the universal truth-claims that characterize each religion. To this end, first the actual criticisms concerning the interreligious dialogue will be analized, secondly the most distinctive features of the lullian approach will be presented, i.e. doubt and philosophy, and finally a Philosophy of Religions inspired by Llull and current theology will be proposed.
\end{abstract}

Key-words: Ramon Llull, John Hick, Interreligious Dialogue, Inclusivism, Pluralistic Theology of Religions, Philosophy of Religions.

\section{INTRODUCCIÓN}

El objetivo de las siguientes páginas consiste en situar a Ramon Llull (1232-1316) dentro de las discusiones contemporáneas sobre la posibilidad de un diálogo interreligioso y, por

* Una primera versión de este artículo fue leída durante el Seminario Internacional «Raimundo Lúlio e o Diálogo Inter-religioso» organizado por el Instituto Brasileiro de Filosofia e Ciência «Raimundo Lúlio» y el Instituto de Estudos Avançados da Universidade de São Paulo los días 18 y 19 de octubre de 2001 en la Universidade de São Paulo. 
lo tanto, sobre la posibilidad de una coexistencia pacífica de las religiones, destacando la aportación luliana a estos debates. Para ello, procederemos mediante tres puntos:

1) Primero, presentaremos, aunque a grandes rasgos, las dos posturas católicas de mayor peso frente a las demás religiones y a la posibilidad del diálogo interreligioso, a saber, el llamado exclusivismo y su réplica, el inclusivismo. Acto seguido, expondremos la reciente crítica a estas dos, la Teología pluralista de las religiones, la cual pretende que la Iglesia se encuentra ante un dilema ecuménico que le impide entrar en un diálogo interreligioso serio.

2) En segundo lugar, analizaremos bajo las perspectivas y cuestiones que surjan de la descripción del panorama actual la propuesta filosófico-teológica de Llull. Aquí, después de a) presentar brevemente vida y obra de Llull frente al exclusivismo y al inclusivismo, mostraremos cómo b) el mallorquín aporta una interesante solución al supuesto dilema ecuménico con la cual abre la posibilidad para un diálogo pacífico entre las religiones -respuesta cuya expresión máxima es c) el Arte luliana que será estudiada detenidamente en vistas del diálogo interreligioso-.

3) En último término, y a modo de conclusión, relacionaremos los resultados obtenidos por el examen de Llull nuevamente con la teología actual. Aquí habrá que preguntarse hasta qué punto éstos parecen viables también desde la situación moderna para guiar el diálogo interreligioso de nuestros días contribuyendo así a la coexistencia pacífica de las religiones.

\section{EXCLUSIVISMO, INCLUSIVISMO Y EL SUPUESTO DILEMA ECUMÉNICO}

La Iglesia católica, como todas las comunidades de creyentes, ha tenido que ir definiendo desde sus inicios su postura frente a una multitud de religiones divergentes las cuales, al igual que ella, se proclaman vías salivíficas únicas. Ciertamente, no será posible aquí reconstruir minuciosamente y con todos sus matices las posturas defendidas por la Iglesia católica con respecto a esta aparente competencia salvífica a lo largo de su historia. Nos limitaremos, por lo tanto, a presentar las dos posturas más significativas al respecto, así como su reciente crítica, el dilema ecuménico. ${ }^{1}$

La primera de estas dos posturas, el exclusivismo, pretendía que la Iglesia católica fuera la única vía salvífica en sentido exclusivo, esto quiere decir que Dios se ha entregado al hombre sólo en Jesucristo cuya presencia se prolonga sólo por la Iglesia, de manera que fuera de la Iglesia es imposible participar de la gracia divina. Como dijo uno de los primeros representantes del exclusivismo, Cipriano, aunque no en vistas de los creyentes de otras religiones, sino apuntando a los renegados de la propia fe cristiana: «Salus extra ecclesiam non est $»-\ll$ No hay salvación fuera de la Iglesia». ${ }^{2}$ Visto desde el exclusivismo, el destino de los creyentes de otras comunidades religiosas sería, pues, la perdición absoluta. Es obvio que esta postura encierra varios problemas teológicos. Ya que, ¿cómo explicar de esta manera satisfactoriamente el destino de todos aquellos que, o por haber nacido antes de la encarnación, o por no tener noticia de ella, no pudieron o no pueden adherirse a la Iglesia católica? ¿Hay que considerar sus almas como perdidas, cuando ellos no son responsables de su ignorancia? Además, fue precisamente esta postura la que sirvió para justificar las cruzadas.

1 Véase para un buen estudio de conjunto de esta cuestión la monografía de Reinhold Bernhardt, $D e r A b$ solutheitsanspruch des Christentums. Von der Aufklärung bis zur Pluralistischen Religionstheologie, Gütersloh, 1990. Así como la breve, pero sugerente nota de Georg Evers, «Die Wetterecke gegenwärtiger Theologie. Stand und Probleme des interreligiösen Dialogs», en: Herder-Korrespondenz, 43 (1989), pp. 75-80.

2 Véase Cyprianus, Opera omnia, pars secunda (CSEL III), Vindobonae, 1871, Ep. 73, 21, p. 795. 
Éstos y otros problemas más llevaron a la Iglesia católica a replantearse la cuestión del exclusivismo con ocasión del Vaticano II (1962-1965) favoreciendo, ahora, una concepción llamada de inclusivista. Así, el teólogo alemán Karl Rahner, ya en 1961, insistió en que no había bastante con remediar, por así decirlo, la situación de los judíos que precedieron históricamente la encarnación, ${ }^{3}$ como hizo Justino con su teoría del «lógos spermatikós» y con él la teología tradicional. ${ }^{4}$ Para Rahner, había que ampliar esta doctrina en vistas de la historia individual de cada persona, afirmando la presencia de la gracia divina como existencial universal. De manera que, para él, también las religiones no-cristianas como objetivaciones de este existencial son «legítimas» (así Rahner literalmente) y tienen su valor propio que hace de ellas vías salvíficas, siempre y cuando la persona que se adhiere a ellas no haya entrado aún en un contacto inmediato con el Cristianismo. Sin embargo, para Rahner esta legitimidad viene fundamentada, a su vez, por el propio Jesucristo. ${ }^{5}$ De tal modo, habla de los creyentes de otras religiones que no han llegado al encuentro con la religión cristiana como de «cristianos anónimos». ${ }^{6}$ Esta expresión, que ha suscitado una gran polémica, es crucial, ya que con ella el teólogo alemán reivindica que las experiencias sobrenaturales que experimentan los creyentes de las demás religiones forman parte de la gracia que se cumple en Cristo. La postura inclusivista no abandona, pues, la pretensión que el cristianismo sea la única vía salvífica, al contrario, reafirma esta pretensión. Pero la matiza en el sentido de que también fuera del cristianismo puede y debe suponerse la gracia divina, aunque ésta siempre está incluída en Cristo. Siguiendo estas líneas, el Vaticano II no sólo recomendó el diálogo con las religiones no-cristianas, sino que reconoció su importancia como vías salvíficas, aunque en el sentido limitado que se acaba de exponer. En este contexto, cabe citar, sobre todo, el decreto Nostra aetate promulgado el 28 de octubre de 1964, el cual, muy claramente, se hace eco de la postura inclusivista. ${ }^{7} \mathrm{Y}$ en la misma línea, debe mencionarse el documento vaticano más reciente con el nombre Christianity and the World Religions. ${ }^{8}$

Frente al exclusivismo, la postura inclusivista ofrece la posibilidad de explicar satisfactoriamente cómo también los miembros de otras comunidades religiosas tienen acceso a la salvación. Además, su reconocimiento de que las demás religiones también contienen elementos de gracia abre la posibilidad de un diálogo serio y pacífico entre las religiones en el cual la religión del otro no es vista simplemente como una manifestación de errores y falsedad, sino que también es portadora de la verdad.

Ahora bien, aunque la postura inclusivista haya sido valorada generalmente como un gran logro incluso por sus críticos, ${ }^{9}$ éstos afirman que, a pesar de todo, es preciso ir más allá no solamente del exclusivismo, sino también del inclusivismo. Porque, según sostienen los representantes de la Teología pluralista de las religiones, ${ }^{10}$ al no abandonar la idea de que Cristo sea la única vía hacia la salvación, el inclusivismo no hace más que recaer en los mismos problemas que el exclusivismo, sea ya sobre un nivel más elevado. Y esto por la siguiente razón: mientras que el exclusivismo niega rotundamente a las demás religiones la posibilidad de acceder a la verdad salvífica, el inclusivismo sí que les otorga esta verdad, pero siempre conce-

3 Véase el artículo fundamental de Karl Rahner, «Das Christentum und die nichtchristlichen Religionen», en: Id., Schriften zur Theologie, 16 vols., Zurich, 1967-1984, aquí vol. V, pp. 136-158.

4 Véase Justinus, Apologia (PG VI), París, 1857, I, 5, 44 y 46.

5 Véase Karl Rahner, art. cit., p. 143.

6 Véase ibid., p. 154.

7 Véase la nota 41 más adelante.

8 Véase Christianity and the World Religions, Roma, 1997.

9 Así, por ejemplo, Paul F. Knitter, Ein Gott-viele Religionen. Gegen den Absolutheitsanspruch des Christentums, Munich, 1988, pp. 62-63.

10 Para una orientación sobre la teología pluralista de las religiones, véase el volumen colectivo editado por John Hick y Paul F. Knitter, The Myth of Christian Uniqueness. Toward a Pluralistic Theology of Religions, Maryknoll, 1987, con colaboraciones de Langdon Gilkey, Raimundo Panikkar y Stanley J. Samartha entre otros.' 
diéndola en función de su relación con la verdad cristiana, de manera que el cristiano parece que no pueda entrar en un verdadero diálogo con los creyentes de otras religiones. A este respecto, uno de los críticos más famosos del inclusivismo, John Hick, ha querido hablar del «Ecumenical Catholic's Dilemma», ${ }^{11}$ es decir, del dilema que se le presenta al creyente católico ecuménico que sigue la doctrina inclusivista como se encuentra, por ejemplo, en el documento Christianity and the World Religions. Concretamente, y dicho con las palabras del propio Hick, este dilema consiste en lo siguiente:

Lógicamente uno no puede afirmar la superioridad única del Cristianismo, sin 'considerar, ya de antemano, las demás religiones como imperfectas e inferiores'. Es imposible reconciliar la pretensión tradicional de la superioridad única del Cristianismo con la actitud abierta que se requiere para el verdadero diálogo interreligioso. ${ }^{12}$

En tal diálogo, así la crítica de Hick y otros, el cristiano nada tiene que aprender del otro, porque su verdad es una verdad incuestionable, a la cual pone al origen de la verdad de todas las otras religiones siempre y cuando encuentra en ellas algo de verdadero. Más que ante un diálogo estaríamos entonces ante un monólogo. Es por este motivo que Hick, y con él todo un movimiento importante en la teología contemporánea, apunta a la necesidad de dar un paso más hacia delante y, como dicen sus representantes, «cruzar el Rubicón»: para esto deberíamos despedirnos no tan sólo del exclusivismo, sino también del inclusivismo en la medida en que ambos mantienen el carácter único de la verdad cristiana, al mismo tiempo que deberíamos afirmar la verdad relativa de las diferentes religiones. Ya que, según los teólogos pluralistas, es precisamente este concepto de unicidad que nos impide entrar en un diálogo serio y pacífico con las demás religiones. Así, para ellos, todas las religiones deben considerarse manifestaciones de lo divino, sin que ninguna de ellas tuviera derecho sobre las otras a reclamar que únicamente ella fuese la vía salvífica por excelencia, sea ya en sentido exclusivo o inclusivo. Ante el aparente problema que no puede haber diálogo ni paz si se insiste en la verdad única, los teólogos pluralistas apuestan, pues, a favor del diálogo y contra la verdad única.

No es aquí el lugar para advertir los numerosos problemas internos que surgen a raíz de esta concepción sobre todo con referencia a sus consecuencias para su noción de la verdad, pero también, y quizá este argumento sea más decisivo aún, en cuanto a la manera de entender e interpretarse las religiones a sí mismas. ${ }^{13}$ Lo que, en cambio, pretendo hacer a continuación es demostrar cómo desde la apologética luliana sí es posible, a mi modo de ver, entrar en un diálogo serio y pacífico con las religiones no-cristianas sin que los dialogantes tengan que deshacerse, por esto, de la pretensión de que sus respectivas religiones sean las vías salvíficas por excelencia.

11 La crítica de Hick fue publicada por primera vez bajo el título «The Latest Vatican Statement on Christianity and Other Religions», en: New Blackfriars, 79 (1998), pp. 536-543, ahora se encuentra editado nuevamente en John Hick, Dialogues in the Philosophy of Religion, Hampshire, 2001, pp. 161-168.

12 John Hick, art. cit., p. 168 (según la nueva edición): «[..] one cannot logically affirm the unique superiority of the Christian faith without 'considering other religions in advance as imperfect and inferior'. It is impossible to reconcile the traditional claim to the unique superiority of Christianity with the outlook required for genuine interreligious dialogue». La comillas señalan que Hick cita al texto mencionado en la nota 8.

13 Véase para una sugerente crítica a la teología pluralista el libro editado por Gavin D'Costa, Christian Uniqueness Reconsidered. The Myth of a Pluralistic Theology of Religions, Maryknoll, 1990, que contesta directamente al libro citado en la nota 10. Así como Reinhold Bernhardt, op. cit., pp. 199-225. 


\section{RAMON LLULL Y SU SISTEMA FILOSÓFICO-TEOLÓGICO COMO POSIBILITACIÓN DEL DIÁLOGO}

\section{a) Una obra y vida al servicio del diálogo: Llull, precursor del inclusivismo}

Propongo, pues, que, guardando en mente este panorama actual y sus problemas, demos ahora un salto hacia atrás en el tiempo, a saber, a la isla de Mallorca donde en 1232 nació Ramon Llull. Los inicios de su carrera intelectual se remontan a mediados del siglo XIII cuando el estudioso mallorquín servía al rey de Mallorca, Jaume II, primero como su preceptor y luego como senescal. En la corte real, Llull, entonces un joven galán, se abandonaba a la poesía trovadoresca para cortejar las damas de la nobleza. Aunque estos primeros ensayos literarios no se hayan conservado, sabemos de ellos a través de la Vita coaetanea, la autobiografía que Llull dictó a un cartujano de Vauvert. ${ }^{14}$ Ésta, además informa que fue una noche del año 1263 , mientras Llull estaba en su cámara componiendo precisamente uno de estos cantos amorosos, cuando su vida daría un giro decisivo al aparecérsele Cristo crucificado. Dicha aparición se le volvió a repetir en las siguientes noches, hasta que Llull, como respuesta a estas apariciones, establecería las tres siguientes metas para su vida: sufrir el martirio al servicio de Cristo, escribir el «mejor libro del mundo contra los errores de los infieles» y fundar una escuela de idiomas para las exigencias de la misión. ${ }^{15}$

Es sabido que la segunda de estas metas, la conversión de los infieles, no mediante la espada, sino con la pluma, era para Llull, a diferencia de muchos autores medievales, no tan sólo un reto intelectual, mas una exigencia existencial. Porque sin duda alguna, Llull tuvo ocasión de convencerse de la necesidad política de una concordancia religiosa en su isla natal que fue reconquistada por Jaume I en 1229, así como también del fracaso de la apologética tradicional de su tiempo. Ésta, basándose sobre todo en la exégesis de la Biblia, aún podía dar algún resultado en el discurso con los judíos los cuales compartían al menos el Antiguo Testamento con los cristianos. En el caso de los musulmanes, sin embargo, era más difícil fijar un punto de partida común. Por lo tanto, si Llull quería escribir «el mejor libro del mundo contra los errores de los infieles», se le planteaba la necesidad de escribir una obra misionera diferente a todas las que existían hasta entonces. Ésta debía partir de los presupuestos comunes de todas las religiones, es decir, afirmar las verdades que en las religiones no-cristianas se contienen, así como hace el inclusivismo, para llegar desde ese punto de arranque a la religión verdadera por excelencia, al cristianismo. Eso sí, no pudo Llull aún extraer de esto todas las consecuencias dogmáticas actuales y reconocer las demás religiones, al menos en cierta medida, como vías salvíficas. ${ }^{16}$ Ahora bien, hasta que Llull pudo cumplir con su segunda meta, deberían transcurrir más de diez años, en los cuales se dedicó al estudio de la filosofía y de la lengua árabe, componiendo la Lògica de Gatzzell así como el importante Llibre de contemplació en Déu. Pues le faltaba la intuición clave de cómo confeccionar dicho libro contra los infieles, ya que el know-how, por así decirlo, para hacer este libro, no lo recibió hasta el año 1274 cuando, como

14 Esta obra, que es una de las fuentes principales sobre los datos de la vida del Beato, está publicada en el tomo número VIII de las ROL. - A parte de los datos extraíbles de esta autobiografía así como las indicaciones implícitas en las demás obras lulianas, resulta muy útil la nueva recopilación de documentos sobre Llull por parte de Jocelyn N. Hillgarth, Diplomatari lul lià: documents relatius a Ramon Llull i a la seva familia, Barcelona, 2001.

15 Véase ROL VIII, pp. 274-276: «[...] quod melius sive maius servitium Christo facere nemo posset, quam pro amore et honore suo vitam et animam suam dare. [...] quod ipse facturus esset postea unum librum, meliorem de mundo, contra errores infidelium. [...] quod iret ad papam, ad reges etiam et principes christianos, ad excitandum eos [...], quod constituerentur [...] monasteria, in quibus electae personae religiosae [...] ponerentur ad addiscendum praedictorum Saracenorum et aliorum infidelium linguagia [...]»

16 No nos entretendremos aquí en presentar detalladamente todos los elementos inclusivistas en Llull así como las diferencias que hay entre la postura luliana y el inclusivismo. Para esto, remito al trabajo de Walter Andreas Euler, Unitas et pax. Religionsvergleich bei Raimundus Lullus und Nikolaus von Kues, Würzburg, 1990, esp. pp. 255-262. 
informa de nuevo la Vita, estando en el Puig de Randa fue iluminada su mente por Dios quien le daba «forma» y «manera» para hacer tal libro. ${ }^{17}$ A partir de esta iluminación a la cual Llull debe su sobrenombre Doctor illuminatus y por la cual recibe el método del libro a redactar que será el Arte-, la producción literaria apologética de Llull así como su actividad misionera práctica ya no cesarían. ${ }^{18}$ De esta suerte, Llull durante toda su vida iría buscando entrar en un diálogo que se fundamentaba en un reconocimiento inclusivista de las verdades contenidas en las demás religiones, por lo que se merece ser considerado uno de los protagonistas del diálogo interreligioso de la Edad Media, si no su mayor representante. Y lo fue no solamente en la Edad Media, sino, como quiero ir demostrando a continuación, lo puede seguir siendo también para nosotros en la actualidad.

\section{b) Llull y el supuesto dilema ecuménico: dudar y filosofar como soluciones}

Para apreciar con mayor claridad esta actualidad que reclamamos para Llull, veamos ahora su actitud frente al problema que nos fue presentado por la crítica al exclusivismo y al inclusivismo en el apartado anterior, es decir, el dilema del católico ecuménico — título que sin duda alguna también corresponde a Llull—. La pregunta que parecía llevar a este dilema era, para recordarla, la siguiente: ¿Es posible afirmar que la propia religión, aquí el cristianismo, sea la vía salvífica por excelencia, ya sea desde una perspectiva inclusivista, y entrar, al mismo tiempo, en un diálogo abierto con representantes de otras religiones? Llull, evidentemente estaba convencido de que su religión era la única vía salvífica, e, incluso, fue muy pesimista respecto a la fuerza salvífica de las otras religiones, a pesar de mantener, como se ha dicho, una postura inclusivista en cuanto a la posibilidad de que las demás religiones contuvieran elementos de verdad. Así, en diversas ocasiones, como en el Blaquerna, lo encontramos postrándose ante la cruz en lágrimas pidiendo a Dios que le ayude en la conversión de los infieles para que no caigan en perdición eterna. Por lo tanto, el supuesto dilema del católico ecuménico no solamente es aplicable a Llull, sino que aquí se presenta de manera más radical aún.

Pues bien, parece que Llull era consciente de este aparente dilema, pero que, no obstante, creyó posible mantener un diálogo serio y pacífico con las demás religiones. Un pasaje muy significativo a este respecto se encuentra en la ya mencionada Lògica de Gatzzell, una poesía doctrinal, que Ramon Llull redactó aún antes de recibir la intuición de su Arte. En vistas de las disputas con los judios y musulmanes, aquí Llull apunta precisamente al dilema descrito por Hick, ya que éstos por creerse portadores únicos de la verdad; según Llull, no entran en un diálogo serio y pacífico sobre las religiones:

Así lo hacen los infieles / que no creen que el Dios del cielo / sea en santa trinidad, / ni que fue encarnado por santa María, / porque, ya antes de empezar a razonar, / no creen y dicen que no, / y porque no creen al principio, / luego su intelecto / no tiene con qué ir a buscar / lo que podría encontrar / si no fuera impedida su virtud / por la imposibilidad / la cual cree / al comenzar a disputar; / a éstos [es decir, los infieles] les valdría más dudar, / ya que por dudar se muestra / lo que es posible. ${ }^{19}$

17 Véase ROL VIII, p. 280: «In quo [monte], cum iam stetisset non plene per octo dies, accidit quadam die, dum ipse staret ibi caelos attente respiciens, quod subito Dominus illustravit mentem suam, dans eidem formam et modum faciendi librum, de quo supra dicitur, contra errores infidelium».

18 No pueden presentarse aquí las obras apologéticas que Llull escribió, ni siquiera sus diálogos interreligiosos. Para esto véase el estudio exhaustivo, que resume muy bien el status quaestionis a la vez que abre perspectivas interesantes sobre el tema, de Fernando Domínguez, «Der Religionsdialog bei Raimundus Lullus. Apologetische Prämissen und kontemplative Grundlage», en: Klaus Jacobi (ed.), Gespräche lesen. Philosophische Dialoge im Mittelalter, Tubinga, 1999, pp. 263-290.

19 Ramon Llull, La ld̀gica del Gatzzell, en: Jordi Rubió i Balaguer, Ramon Llull i el lul lisme, Barcelona, 1985 , pp. 144-164, aquí pp. 152-153, versos 641-666: «Aytal vos han li infidel / qui descreson que Deus del cel/sia en 
Llull se lamenta, pues, que los infieles no entran en el juego del diálogo, ya que creen de manera exclusiva en su verdad y, por ello, afirman, ya desde buen principio, que los dogmas de la fe católica son imposibles, así como, según Hick, nadie puede entrar en un diálogo si cree superior su verdad. Pero Llull, en este mismo pasaje, ya esboza una posible solución para este dilema introduciendo el concepto de duda que se caracteriza precisamente por tomar una postura neutral con referencia a la afirmación y la negación. Así, en el diálogo, la duda inicial debe admitir la posibilidad de la verdad del adversario.

Como otra muestra de que Llull conocía los peligros de tal dilema, puede aducirse un pasaje del Blaquerna, una de las primeras novelas burguesas europeas que narra el ascenso de su protagonista homónimo por todos los cargos eclesiásticos hasta el papado. Aquí, Llull nos cuenta que cuando un cardenal en Roma oyó algún día que en la ciudad había un judío y un cristiano que se disputaban con mala voluntad por sus respectivas religiones, fue a verlos para decirles lo siguiente:

Aún tiene otra naturaleza el entendimiento para entender, a saber, que uno afirme que aquella cosa que la voluntad quiere que el entendimiento entienda sea una cosa posible; ya que, si antes de que el entendimiento la entienda, afirma que tal cosa es imposible, el entendimiento no estará capacitado para entender la posibilidad o imposibilidad que se desprende de esta cosa. [...] y si con todo esto uno no puede entender, conviene que recorra a la obra Arte abreviada de encontrar verdad. ${ }^{20}$

Evidentemente, el cardenal se encuentra ante el mismo problema que el que venimos de exponer para la Lògica de Gatzzell: los dos dialogantes afirman cada uno estar en posesión exclusiva de la verdad única, $y$, por consecuencia, afirman cada uno categóricamente la imposibilidad de las verdades del otro. Y también en este caso, el consejo de Llull sigue siendo no decantarse al principio del diálogo ni por un lado ni por el otro, sino creer posible también la opinión del adversario.

La conclusión que podemos inferir de estos dos ejemplos es la siguiente: Para Llull, todo diálogo interreligioso debe partir de lo que en nuestros días se ha llamado el «principle of charity» (Donald Davidson), es decir, la suposición que lo que nos quiere decir el otro tenga posiblemente un contenido proposicional que sea verdadero. Y esto sólo es una cara de la moneda, porque al mismo tiempo, también las creencias propias, al entrar en el diálogo, deben formularse de manera dudosa, es decir como verdades meramente posibles, porque sino, no estaríamos en condición para reconocer la posible verdad de la religión de nuestro interlocutor. Seguramente, Hick y con él los teólogos pluralistas hasta aquí estarían plenamente de acuerdo con Llull, sacando de todo esto la conclusión de que, precisamente para garantizar esta actitud abierta hacia la posible verdad del otro, hay que concluir que no hay religión que pueda reclamar para sí misma el título de ser la religión por excelencia.

Llull, en cambio, no llega a estas consecuencias escépticas y de cierta manera precipitadas: Para él, esta regla fundamental de la hermenéutica que acabamos de presentar no implica que sea imposible falsificar lo que dice el otro y probar la propia posición o al revés; sino

santa trinitat, / ni'n santa Maria encarnat, / car al començ de la rahó / descreon e dien que no, / e cor descreon en primer, / lur enteniment en derrer / no ha ab que vaya cercar / so que ell pogra atrobar / si no li'nbarguas sa virtut / l'inpossibol, qui es creut / al començar del disputar; / a qual los valgra mays duptar, / car per duptar es demostrat / ço que es possibilitat».

20 Ramon Llull, Llibre de Evast e Blanquerna, ed. Salvador Galmés, 4 vols., Barcelona, 1935-1954, vol. II, pp. 157-158: «Altra natura a l'enteniment a entendre, ço és a saber, que hom aferm possible cosa ésser aquella cosa que la volentat vol que-l enteniment entena; cor si, ans que-l enteniment la entena, aferma inpossibilitat ésser en aquella cosa, l'enteniment no serà aparellat com pusca entendre la possibilitat o impossibilitat qui serà intel ligible en aquella cosa. [...] e si tant és que per totes aquestes no puscha entendre, cové que hom recorra a la Art breuyada d'atrobar veritat». 
que, únicamente, pretende que al principio de todo diálogo esté la suposición de que las aserciones del otro puedan ser verdaderas y las propias falsas. Pero esta suposición inicial de ninguna manera le lleva a una relativización de las diferentes religiones cuyas respectivas pretensiones de verdad deberían permanecer en suspensión. Frente a este problema, en el Llibre de demostracions, Llull precisa lo que entiende por suponer la posibilidad de que la religión del otro sea verdadera de la siguiente manera:

La segunda condición es que uno afirme en cuanto al intelecto la posibilidad de entender por necesarias razones [...]; ya que si al principio se negara esta posibilidad, el intelecto no tendría manera ni remedio de cómo entender e investigar si le es cosa posible o imposible entender $[\ldots]^{21}$

Lo importante aquí es que la posibilidad de que las aserciones de una religión cualquiera sean verdaderas no es una posibilidad indecidible, sino que, al admitir esta posibilidad, el dialogante admite la posibilidad de que las preguntas que se debaten pueden ser formuladas y resueltas todas por medio del intelecto o de la razón. ${ }^{22}$ Así, la posibilidad de las diferentes religiones de ser verdaderas, que necesariamente hay que suponer al iniciarse el diálogo, para Llull, a diferencia de Hick, no es una posibilidad tout court, sino que es una posibilidad en cuanto que sus aserciones son todas posibles objetos de la razón. Lo que se sigue, pues, de esta posibilidad no es un relativismo, sino precisamente la necesidad de comprobar racionalmente la pretensión de verdad de las diferentes posiciones que están en juego. La prioridad de una religión sobre las otras no se concederá ya desde los argumentos inherentes a cada una de ellas, sino que el criterio de su verdad será su inteligibilidad a la luz de la razón. He aquí una primera respuesta de Llull al supuesto dilema de Hick la cual insiste en la fuerza de la razón filosófica que, esto sí, arranca de la duda, pero que, al mismo tiempo, lleva más allá del relativismo.

Ahora bien, siempre se ha insistido en que las reglas del razonamiento filosófico son universales para todos los hombres. No obstante, resulta más fácil afirmar que el diálogo de las religiones debe enfocarse desde la razón o, incluso, desde la filosofía que no llevar a cabo este propósito. Porque, ¿cuál sería esta razón, o filosofía? ¿La razón o filosofía práctica o la teórica? E incluso si pudiéramos decidirnos por una u otra de ambas, $\Varangle$ a cuál de sus respectivas manifestaciones nos referimos: a la lógica, la ontología, la teología filosófica, la ética, la política o cualquiera otra de las llamadas ciencias del espíritu? El mismo criterio de la razón universal se nos muestra así en una gran variedad de facetas, y más aún en un tiempo como el nuestro, donde predomina una fragmentación de los diferentes ámbitos de la razón. Es por este motivo que, para especificar la razón que debe guiar el diálogo inclusivista entre las religiones y codificar sus reglas, Llull concibe una nueva ciencia, su Ars. Así que, como ya aconsejó el cardenal a los dos dialogantes del Blaquerna, «conviene que se recorra al Arte abreviada de encontrar verdad», si se quiere mantener un diálogo serio y pacífico que no niegue de antemano la verdad del otro, pero que tampoco lleve a una relativización de los diferentes credos como él de la Teología pluralista. La respuesta al dilema ecuménico que ofrece Llull con sus con-

21 Ramon Llull, Llibre de demostracions, ORL, XV, p. 4: «Segona condició es que hom aferm possíbol cosa esser al enteniment entendre per necessaries rahons [...]; cor si en lo comensament era negada possibilitat, l'enteniment no auria endressament ni aparellament com pogués entendre ni ensercar si a ell es possíbol o impossíbol cosa entendre [...]»

22 La relación complementaria de razón y fe es uno de los rasgos más característicos del pensamiento de Llull quien se opuso con toda su fuerza al intento averroísta de separar ambas -intento que también en la actualidad sigue teniendo sus defensores-. Véase para la actitud de Llull frente a la posición averroísta, entre otros, el artículo de José Higuera en Alexander Fidora y José Higuera (eds.), Ramon Llull - Caballero de la fe, Pamplona, 2001, pp. 81-109. 
ceptos de duda y de razón, y que hemos esbozado aquí, remite, pues, ella misma al Arte luliana. Debemos exponer, por lo tanto, el Arte.

\section{c) El Arte luliana como filosofar universal e integral}

La interpretación del Arte luliana ha oscilado desde el renacimiento hasta nuestros tiempos entre dos polos: de esta manera, aún dos eruditos tan importantes y relativamente recientes como Joseph Bochenski y Wilhelm Risse clasificaron el Arte luliana de «lógica matemática» y de «metafísica», respectivamente. ${ }^{23}$ Sin embargo, ambas interpretaciones no llegan a describir adecuadamente el estatuto epistemológico del Arte como ciencia misionera y del diálogo interreligioso. Pero vayamos por pasos analizando el Ars brevis que junto al Ars generalis ultima es la última expresión del Arte luliana:

Para empezar, cabe recordar que el Arte luliana descansa sobre dos pilares, siendo el primero de ellos el llamado alfabeto que Llull introduce al principio del Ars brevis y que se puede resumir de la siguiente manera: ${ }^{24}$

\begin{tabular}{|l|l|l|l|l|l|l|}
\hline & Princip. abs. & Princip. rel. & Preguntas & Sujetos & Virtudes & Vicios \\
\hline B & Bonitas & Differentia & Utrum? & Deus & Iustitia & Avaritia \\
\hline C & Magnitudo & Concordantia & Quid? & Angelus & Prudentia & Gula \\
\hline D & Aeternitas & Contrarietas & De quo? & Caelum & Fortitudo & Luxuria \\
\hline E & Potestas & Principium & Quare? & Homo & Temperantia & Superbia \\
\hline F & Sapientia & Medium & Quantum? & Imaginativa & Fides & Accidia \\
\hline G & Voluntas & Finis & Quale? & Sensitiva & Spes & Invidia \\
\hline H & Virtus & Maioritas & Quando? & Vegetativa & Caritas & Ira \\
\hline I & Veritas & Aequalitas & Ubi? & Elementativa & Patientia & Mendacium \\
\hline K & Gloria & Minoritas & $\begin{array}{l}\text { Quo modo } \\
\text { / cum quo? }\end{array}$ & $\begin{array}{l}\text { Instrumenta- } \\
\text { tiva }\end{array}$ & Pietas & Inconstantia \\
\hline
\end{tabular}

La primera serie de principios que aquí se reproducen suelen llamarse principios absolutos, aunque esta denominación no es de Llull, quien en sus primeras obras los nombraba dignitates pasando a nombrarlos luego simplemente principia. ${ }^{25}$ Tanto la palabra dignitas como el nombre de principia remiten a la tradición aristotélica de los Analitica posteriora, donde se establece que cada ciencia parte de principios per se nota que no pueden ser comprobados, al menos no por la misma ciencia. Siguiendo esta tradición, estos principios también para Llull son indemostrables. Es más, son los mismos atributos de Dios que, como causas ejemplares, son a la vez los principia essendi y los principia intelligendi de la creación. Es por este motivo que no pueden ser probados, ya que son la condición de la posibilidad del ser y del conocer. Pero - y con esto volvemos a la intención dialogadora de Llull- tampoco hace falta probarlos, porque representan un lugar común de las tres grandes religiones de libro.

23 Véase Joseph Bochenski, Formale Logik, Munich, 1956, pp. 318-320, donde Llull aparece como precursor del cálculo lógico, y Wilhelm Risse, Die Logik der Neuzeit, Stuttgart-Bad Canstatt, 1964, p. 532, donde el autor sostiene todo el contrario, a saber, que el Arte luliana es «in ihrem Grunde metaphysisch, nicht logisch».

24 Véase Raimundus Lullus, Ars brevis, ed., trad. e introd. Alexander Fidora, Hamburgo, 1999, p. 4; el esquema es mío.

25 Igualmente en el Ars brevis donde Llull ya no habla de las dignidades. Debo esta importante precisión así como otras enmiendas a mi edición del Ars brevis a la recensión de Anthony Bonner en Studia Lulliana, 40 (2000), pp. 131-132. 
Mientras que estos atributos divinos, según Llull, son indistinguibles cuando están en Dios, sí que se pueden diferenciar y relacionar en cuanto están realizados en la creación, por lo cual Llull introduce, en segundo lugar una serie de principios relacionales como «diferencia», «concordancia», «contrariedad», etc. que abarcan todos los seres intra-mundanos. Con esto, la cosmovisión de Llull posee dos ejes, uno vertical que religa la creación a su causa trascendente mediante los principios absolutos, siendo estos las causas ejemplares del mundo, y otro horizontal que describe el dinamismo entre las criaturas a partir de las diferentes relaciones que se dan entre ellas. También esta convicción, es decir, que las dignidades son idénticas en Dios, pero que fuera de él se distinguen, es un lugar común de las tres grandes religiones.

Como también se desprende de las demás series de principios Llull parte, pues, en su ciencia de unos principios materiales que representan unos contenidos extramentales comunes a todas las grandes religiones. Y estos no sólo son ontológicos, sino también éticos, como se ve con las virtudes y los vicios del alfabeto. Con esto no solamente vemos corroborado su inclusivismo, sino que también se está ante la primera importante diferencia entre su Arte y la lógica formal: mientras que ésta tan sólo garantiza la corrección formal del silogismo, el Arte parte de unos principios que no sólo expresan procedimientos, sino realidades ontológicas y éticas.

¿Cabe decir entonces que la ciencia luliana es metafísica, ya que además se ha puesto en relación el uso de los principios en Llull con la teoría de la ciencia de Aristóteles? A primera vista, podría parecer que hay que identificar ambas ciencias, ¿pero cómo integrar en esta perspectiva los atributos divinos que nos presentan a Dios no como primer motor, sino con los rasgos característicos del Dios personal? Parece, pues, que con respecto al primer pilar del Arte ni la interpretación del mismo como lógica ni como metafísica es convincente.

Hasta aquí se ha expuesto el aspecto material del Arte, cabe ahora presentar su segundo pilar, que consiste en su carácter formal. Antes de empezar a exponer las figuras y para mejor entenderlas, se debe destacar la primera de las preguntas de la tercera columna del alfabeto, a saber, la pregunta «si», que en el Ars brevis, ed. cit., p. 28, nos remite al contexto de la duda sistemática que hemos expuesto en el último apartado:

B. [La pregunta] 'si' tiene tres especies: a saber, la duda, la afirmación y la negación, para que el intelecto suponga al principio las dos partes de una cuestión como posibles, y no se ligue con creer, ya que éste no es su acto, sino el entender. $Y$ debe aceptar aquella parte con la cual su entendimiento sea mayor. Porque ésta tiene que ser verdadera.

Una vez más, Llull insiste en la necesidad de acercarse al diálogo interreligioso desde una perspectiva que elimine todo prejuicio que pueda afectar la discusión filosófica sobre las diferentes materias, ya sean religiosas o de otro tipo. El Arte luliana sigue, pues, la pauta de tomar en consideración todas las aserciones posibles evaluándolas por su inteligibilidad. ${ }^{26}$ Es para esto que Llull elabora sus célebres figuras que no hacen otra cosa que generar sistemáticamente todas las posibles combinaciones o aserciones que puedan formarse de los principios materiales compartidos por todas las religiones. Veamos pues las figuras:

La primera de las cuatro figuras (véase el apéndice), la Figura A, demuestra la mutua predicabilidad y la convertibilidad de los principios absolutos en Dios. Sin embargo, esta figura no es exclusivamente teológica, sino que también se aplica a la creación en tanto que en ella se hallan realizados los principios absolutos. Por tanto, dice Llull, que esta figura sirve para descender de lo universal a lo particular y viceversa. Es este el camino que al tratar de los principios se había apostrofado como la dimensión vertical del Arte.

26 Para un análisis detenido de esta regla que puede ser muy provechoso tener en cuenta para las ideas que aquí desarrollamos, léase Esteve Jaulent, «Breu consideració sobre la Regla B de l'Ars lulliana», en: Revista internacional d'humanitats, $2 / 2$ (1999), pp. 23-36. 
La segunda figura, de nombre $\mathrm{T}$, pone en orden sistemático los principios relacionales, agrupando cada tres de ellos en las tres puntas de un triángulo. Así, el triángulo verde, por ejemplo, contiene en sus ángulos «diferencia», «concordancia» y «contrariedad», términos que se distinguen según el ámbito de la realidad al cual son aplicados. Con esta figura, Llull despliega ante los ojos de sus lectores la compenetración horizontal de la cual se ha hablado antes.

Las figuras A y $\mathrm{T}$ son retomadas y unidas por Llull en la tercera figura, que es a la vez la primera figura de carácter combinatorio consistiendo de 36 casillas con combinaciones binarias de la forma $\mathrm{BC}, \mathrm{BD}, \mathrm{BE}$, etc. que se agrupan en ocho columnas. Estas 36 casillas resultan de nueve elementos combinados de dos en dos sin repetición: 9 ! / [(9-2)! × 2! $]=36 .{ }^{27}$ Cada una de estas letras puede ser tanto predicado como sujeto de una predicación, pudiéndosele atribuir además tanto el valor de los principios absolutos como el de los principios relacionales. Al procedimiento de desarrollar el contenido polisémico de cada casilla, Llull le da el nombre de evacuatio. Con ello, Llull pretende encontrar una cópula que relacione el predicado y el sujeto para llegar a juicios seguros. ${ }^{28}$

Así como la tercera figura resume las dos figuras precedentes, la cuarta y última figura integra todas las figuras hasta aquí expuestas. Esta figura consiste de tres discos que llevan las letras del alfabeto luliano en su periferia, siendo los dos interiores de ellos móviles. Si se hacen rodar estos discos, resultan 252 combinaciones ternarias sin repetición ${ }^{29}$ significando para Llull la letra que está en el centro de la combinación el terminus medius del silogismo. En la combinación ternaria $\mathrm{BCD}$, por ejemplo, $\mathrm{BC}$ sería la propositio maior, $\mathrm{CD}$ la propositio minor, $\mathrm{C}$ el terminus medius y BD la conclusión. La función de esta figura es precisamente forjar al investigador los términos medios para que pueda llegar a conclusiones seguras. Para acabar de describir esta figura, cabe señalar que las combinaciones ternarias resultantes de ésta son como las combinaciones de la figura anterior- ambivalentes, ya que pueden recibir tanto el valor de los principios absolutos como el de los principios relacionales. Para diferenciar estos significados, Llull esboza en la quinta parte del Ars brevis las primeras columnas de una Tabula que en su totalidad cuenta con 84 columnas de 20 elementos cada una, es decir, con un total de 1680 combinaciones.

Ahora bien, el número elevadísimo de preguntas que Llull genera de esta manera, para presentarlas al juicio racional, es expresión de su afán de querer abarcar toda aserción posible sin excluir ninguna de ellas de antemano. Se puede decir, pues, que la función de las figuras es garantizar que en el diálogo interreligioso ninguna combinación posible de los principios básicos quede fuera de consideración, al mismo tiempo que su desplegamiento sistemático facilita a la razón su tarea de juzgar de ellas y llegar a la verdad.

A propósito del primer pilar del Arte luliana, sus principios, ya se han marcado algunas diferencias importantes respecto a la lógica y a la metafísica. Falta situar el segundo componente del Arte frente a estas dos ciencias, a saber, su aspecto formal. En primer lugar, podría parecer que son precisamente las figuras las que hacen del Arte una lógica por excelencia. Sin embargo, ateniéndonos a la finalidad de las figuras expuestas por Llull, hay que señalar una diferencia capital: ni las figuras, como tampoco los principios, pretenden solamente garanti-

27 Una buena introducción a los conceptos matemáticos de Llull se encuentra en Umberto Eco, La búsqueda de la lengua perfecta en la cultura europea, trad. $\mathrm{M}^{\mathrm{a}}$. Pons, Barcelona, 1994; véase todo el capítulo «El Ars magna de Ramon Llull», y esp. pp. 55-64.

28 Llull mismo define el objetivo de esta figura en su Ars brevis, ed. cit., p. 18, de la siguiente manera: «In qualibet camera sunt duae litterae, in ea contentae; et ipsae significant subiectum et praedicatum. In quibus artista inquirit medium, cum quo subiectum et praedicatum coniunguntur; sicut bonitas et magnitudo, quae coniunguntur per concordantiam, et huiusmodi. Cum quo medio artista intendit concludere et propositionem declarare».

29 Este número resulta de la siguiente operación: Si se fija un elemento del círculo exterior, a éste se le pueden contraponer 8 ! / [(8-2)! $\times 2$ !] = 28 combinaciones binarias. Repitiendo esta operación con las nueve letras del círculo exterior, se obtienen $9 \times 28=252$ combinaciones ternarias. 
zar la corrección formal del silogismo, sino que van más allá. En efecto, pretenden ayudar al investigador a encontrar la cópula de una proposición o el término medio del silogismo mismo, así que también ellas se vuelven materiales en el sentido de que són «poieticas». El Arte luliana quiere ser, al igual que la lógica, una ciencia demostrativa, pero quiere ser más que esto, porque a la vez aspira a ser inventiva para encontrar las cópulas y los términos medios. ${ }^{30}$ Por tanto, el Arte no tan sólo parte de unos principios materiales, sino que al final vuelve a ellos forjando la materia, la base, para el silogismo, que a su vez puede servir como base de nuevos razonamientos o, incluso, como fundamento de las demás ciencias.

Esto había sido para Aristóteles una de las tareas principales de su ciencia buscada, la metafísica; pero el Arte de Llull también trasciende las limitaciones de esta ciencia, ya que no se limita a considerar a Dios como primer principio, como hace la metafísica, sino que a base de la figura $\mathrm{A}$, y ayudándose de la demonstratio per aequiparantiam, ${ }^{31}$ entra además en la reflexión sobre las relaciones intra-divinas que le permiten abarcar también los misterios de la fe. ${ }^{32}$

El Arte luliana no es, pues, ni lógica ni metafísica, sino que hay que situar su lugar sistemático más allá de éstas. Por esto, Llull mismo en los Introductoria Artis demonstrativae define su ciencia más allá de la separación entre lógica y metafísica:

Pues la metafísica considera las realidades que se encuentran fuera del alma con respecto a su ser; mientras que la lógica considera las realidades según el ser que tienen en el alma [...] Este Arte, en cambio, como la más alta entre las ciencias humanas, considera el ser tanto de esta manera como de la otra, y de esto se desprende que aquellas se distinguen de ella en la manera de considerar el sujeto. ${ }^{33}$

Con esto, queda claro que el Arte tiene paralelismos con ambas ciencias, pero que es precisamente su peculiar combinación de la perspectiva formal y material de estas ciencias que hace del Arte una ciencia filosófica misionera sui generis. Pues bien, esta es la ciencia que, a los ojos de Llull, cumple los requisitos para servir como base del diálogo inclusivista de las religiones y, a nuestros ojos, también para solucionar los problemas actuales en la discusión sobre el diálogo interreligioso. Me explico: como el teólogo pluralista, también Llull admite que para entrar en un diálogo respetuoso y pacífico con los creyentes de otras comunidades hay que afirmar que estos posiblemente tengan razón, y que él mismo esté equivocado. Sin embargo, su duda no es escéptica como la del teólogo pluralista, sino que es filosófica, ya que Llull da un paso más que éste, reclamando que sí que existe unà instancia desde donde puede resolverse esta duda sistemática, a saber, la razón. Si al final del último apartado nos estábamos preguntando cuál podía ser esta razón, después de lo dicho no cabe duda que el Arte luliana viene a ser la respuesta a esta pregunta: porque el Arte no sólo es una filosofía universal, ya que está abierta para todas las religiones y todas sus aserciones, sino que, a la vez, es una filosofía integral en cuanto que reúne en una misma ciencia las perspectivas de la lógica, la metafísica,

30 El carácter inventivo del Arte ya fue apuntado por Eusebi Colomer en 1979 en su estudio clásico «De Ramon Llull a la moderna informática» reproducido en su libro El pensament als Països catalans durant l'Edat mitjana $i$ el Reniaxement, Barcelona, 1997, pp. 85-112, esp. p. 90. Sin embargo, es mérito indiscutible de Josep Ma. Ruiz Simon el haber estudiado en detalle esta cuestión en su obra Ramon Llull i la teoria escolàstica de la ciència, Barcelona, 1999.

31 Consúltese sobre los tres tipos de demostración en Llull, entre otros, el artículo de Esteve Jaulent, «Arbor scientiae: Immanenz und Transzendenz im Denken Llulls», en: Zeitschrift für Katalanistik, 11 (1998), pp. 8-32, esp. pp. 21-22.

32 Consúltese también para este aspecto el libro de Josep $\mathrm{M}^{\mathrm{a}}$. Ruiz Simon mencionado en la nota 30, esp. pp. 297-306.

33 MOG III, p. 55: «Metaphysica enim considerat res, quae sunt extra animam, prout conveniunt in ratione entis; Logica autem considerat res secundum esse, quod habent in anima [...] sed haec Ars tanquam suprema omnium humanarum Scientiarum indifferenter respicit ens secundum istum modum et secundum illum; et sic patet ut in modo considerandi ex parte subiecti differunts. 
la teología y la ética. ${ }^{34}$ No es, pues, exageración alguna decir que Llull, con esta ciencia universal e integral, efectivamente forja una instancia filosófica para el debate interreligioso que va más allá del relativismo de Hick, pues permite valorar racionalmente la pretensión de verdad de cada una de las religiones desde sus comunes presupuestos lógico-ontológicos y éticos.

Ciertamente, la postura que Llull propone no es nada cómoda para el creyente, ya que exige que éste continuamente esté dispuesto a dudar de su propia creencia por el respeto incondicional a la verdad. Y así oímos decir a Llull mismo en uno de sus viajes a Túnez al final de su vida las siguientes palabras:

Así, Ramon, a medida que iban acudiendo cada día expertos más grandes en la ley de Mahoma, les dijo, entre otras cosas, que él se sabía bien las razones de la ley de los cristianos en todos sus artículos; y que había venido aquí para convertirse a su secta si después de oír las razones de su ley que en su diálogo ellos exponían, es decir, la ley de Mahoma, él las encontrase de mayor validez que las de los cristianos. ${ }^{35}$

Contra los teólogos pluralistas, Llull mantiene, pues, que la validez de las razones filosóficas, entendidas en conformidad con el Arte como filosofía universal e integral, hace posible reconocer una determinada religión como la religión verdadera en sentido eminente. Más aún, para Llull, estas mismas razones son las que pueden exigir una adherencia incondicional a una religión determinada, hasta tal punto que él mismo, como acabamos de ver, pone a disposición su fe católica.

\section{CONCLUSIÓN: TEOLOGÍA PLURALISTA DE LAS RELIGIONES VERSUS FILOSOFÍA DE LAS RELIGIONES}

Frente a la problemática actual que hemos desarrollado en el primer apartado de esta comunicación, creo haber mostrado que Llull, como precursor del inclusivismo, conoció el problema que los representantes de la Teología pluralista de las religiones se plantean bajo el nombre del dilema ecuménico. Sin embargo, no concibió esta problemática como aporética, sino que ofrece una interesante solución que me parece poderse resumir felizmente bajo un título que contrasta con la «Teología pluralista de las religiones», a saber, «Filosofía de las religiones». Creo poder decir que la Teología pluralista de las religiones lleva a su último extremo el concepto de una apología que opera por autoridades, sacando de aquí la conclusión que la primacía entre las religiones es un asunto que no puede decidirse definitivamente. La Filosofía de las religiones, en cambio, defiende un concepto de apología que se guía por una forma integral, por no decir sapiencial, de la filosofía que parte de los presupuestos universales de las religiones y que encuentra su expresión más elaborada en el Arte que acabamos de exponer. De tal modo, la duda luliana no resulta aporética, ni resulta en una relativización de los diferentes credos, sino que sirve como punto de arranque para un diálogo realmente fructífero.

Para acabar esta reflexión, quiero volver, con estas últimas páginas de conclusión, otra vez adelante en el tiempo y trasladar los dos momentos clave de la Filosofía de las religiones de Llull, a saber, la duda y la filosofía, al discurso actual. Empecemos por la duda: podría repli-

34 A este respecto, Eusebi Colomer habla de la «onto-teo-logía» luliana; véase, por ejemplo, su libro $D e$ la Edad Media al Renacimiento: Ramon Llull, Nicolás de Cusa, Juan Pico della Mirandola, Barcelona, 1975, p. 57. Sin duda, este concepto es problemático, sobre todo cuando con él se sugiere una relación entre Llull y el Idealismo alemán, como apunta Esteve Jaulent, «Arbor scientiae...», art. cit., esp. pp. 28-31.

35 Raimundus Lullus, Vita coaetanea, ROL VIII, p. 289: «Raimundus ergo, convocatis paulatim de die in diem peritioribus in lege Machometi, inter alia dixit eis, se bene scire rationes legis christianorum-in omnibus suis articulis; et ad hoc se venisse, quod ipse, auditis rationibus legis eorum, scilicet Machometi, si inveniret illas, habita inter ipsos super his collatione, validiores, quam rationes christianorum, converteretur ad sectam eorum». 
cárseme que la duda no ha sido nunca un concepto positivo, ni en la teología católica, ni en las demás tradiciones religiosas. Y ciertamente es verdad; si por duda se entiende el alejamiento voluntario del hombre de la verdad que posee, esto, en términos tradicionales, es pecado. ${ }^{36} \mathrm{Sin}$ embargo, existe un sentido positivo de duda que viene desde Agustino hasta Charles S. Peirce. $Y$ es en esta segunda tradición donde hay que situar también a Ramon Llull. 'Duda' aquí significa la disposición del hombre de seguir siempre en busca de una verdad mayor y suprema de la que ya posee. Y aunque es creencia católica que en Jesucristo se haya cumplido la revelación de manera irrevocable y, a la vez, insuperable, también para el cristiano queda esta búsqueda como obligación. Porque hasta el cumplimiento del «eschaton», Dios sigue también para él incomprensible en su altura. Una convicción que, por cierto, también compartía Llull. ${ }^{37}$ En este sentido, el cardenal Joseph Ratzinger escribe sobre la duda:

Tanto el creyente como el no-creyente participan, cada uno a su manera, de la duda y de la fe, cuando no se esconden de ellos mismos y de la verdad de su ser. [...] Quizá incluso podría ser la duda, la cual salva a ambos del ensimismamiento, el lugar en donde se dé la comunicación entre ambos. ${ }^{38}$

Estas palabras de Ratzinger corroboran la importancia que también la Iglesia católica concede al concepto de duda para la comunicación entre cristianos, creyentes de otras religiones y no-creyentes. Esta duda unida a la filosofía universal e integral, tiene realmente, como afirma Ratzinger, buenas posibilidades para ayudar a dar un paso adelante en el diálogo interreligioso, el cual no necesariamente tiene que ser un diálogo entre religiones que renuncien a la pretensión de ser las religiones por excelencia, respectivamente.

Ahora bien, ¿qué debe decirse sobre el segundo elemento de la apologética luliana, la filosofía y su relación con la teología? ¿No se han ido separando las diferentes religiones cada vez más de la filosofía, condenando, incluso, los esfuerzos de sus miembros de reconciliar ambas, como fue el caso del «modernismo» en la Iglesia católica? Parece que las religiones, al reclamar ser expresión de una experiencia sui generis se hayan opuesto progresivamente al concepto de razón y de filosofía; y sin duda es así, si por razón y filosofía se entienden los movimientos que han llevado al eclecticismo, al materialismo, al cientificismo y, todavía, al nihilismo. Frente a estas tendencias las religiones se presentan como alternativa bien opuesta. Sin embargo, por ello no deben renunciar a la filosofía en su totalidad. Al contrario, es posible criticar desde la religión a la filosofía, para volver a una filosofía que no se crea autosuficiente en su racionalismo, y que, siendo no solamente una ontología o ética de la inmanencia, se mantenga abierta para las diferentes experiencias de lo trascendente. Y efectivamente, esta filosofía que Llull reivindica con su Arte también se vuelve a reivindicar en nuestros días, como queda patente en la encíclica Fides et ratio de Juan Pablo $\amalg{ }^{39}$ Vamos a citar, aquí, de nuevo a Ratzinger en su comentario a esta encíclica:

36 Véase sobre los diferentes conceptos de duda y su valoración moral desde la teología actual, la entrada s.v. «Zweifel» en Karl Rahner y Herbert Vorgrimler (eds.), Kleines theologisches Wörterbuch, Friburgo en Br., ${ }^{5} 1965$, p. 393.

37 Véase, por ejemplo la tercera condición del prólogo al Llibre de demostracions, ed. cit., p. 4, donde Llull sostiene que a Dios le hay que atribuir mayor nobleza de la que el intelecto humano pueda concebir.

38 Joseph Ratzinger, Einführung in das Christentum. Vorlesungen liber das apostolische Glaubensbekenntnis, Munich, 1990, p. 24: «Der Glaubende wie der Ungläubige haben, jeder auf seine Weise, am Zweifel und am Glauben Anteil, wenn sie sich nicht vor sich selbst verbergen und vor der Wahrheit ihres Seins. [...] Vielleicht könnte so gerade der Zweifel, der den einen wie den anderen vor der Verschließung im bloß Eigenen bewahrt, zum Ort der Kommunikation werden».

39 De las varias publicaciones que han salido con motivo de la encíclica sólo mencionamos aquí Víctor Sanz (ed.), La encíclica 'Fides et ratio' y la filosofía, monográfico del Anuario filosófico 32/3 (1999). 
Lo propio de la fe cristiana en el mundo de las religiones es que sostiene que nos dice la verdad sobre Dios, el mundo y el hombre, y que pretende ser la 'religio vera', la 'religión de la verdad'. [Así que] la cuestión de la verdad es la cuestión esencial de la fe cristiana, y, en este sentido, la fe tiene que ver inevitablemente con la filosofía. ${ }^{40}$

Para Fides et ratio, el vinculo entre una filosofía sapiencial y la fe no sólo es posible, sino, como dice Ratzinger, es «inevitable», o, como sugiere Llull con sus rationes necessariae, ${ }^{41}$ tal vinculo es necesario. Y no solamente lo es para la auto-interpretación de cada una de las religiones, sino que lo es, ante todo, para su diálogo, como también apunta aquí Ratzinger. Es, pues, desde el mismo interior de la Iglesia que se concibe nuevamente, hoy, la necesidad de una filosofía universal e integral para el diálogo interreligioso, así como la propuso Llull hace 700 años.

Sin embargo, al citar dos veces a Ratzinger, no quiero dar lugar a malentendidos, sugeriendo que la teoría del diálogo interreligioso de Llull pudiera ser, también, la política de la Iglesia como institución. La teoría luliana es ante todo una teoría para el diálogo interreligioso entre los creyentes. La Iglesia, en cambio, no puede dudar de su verdad en materias de fe, ni tampoco debe ponerlas bajo el criterio de la razón, al menos no en el sentido de que ésta constituya su verdad. Y esto por un motivo muy simple: ella misma no es sujeto del creer, sino que es su objeto, es decir, es la verdad que debe ser creída y que, esto sí, por cada uno de los creyentes debe ser tratada desde la perspectiva que hemos expuesto a lo largo de estas páginas. Sin embargo, como ella misma es parte de esta creencia no puede cuestionarse a sí misma sin implicarse en contradicciones. Es por este motivo que no creo posible que la Iglesia católica como institución pueda ir más allá de las aserciones sobre el inclusivismo del Vaticano II y del documento Christianity and the World Religions, donde se afirma, como en Rahner, la presencia de la divina gracia en las demás religiones que, así, pueden llevar al hombre a la salvación. ${ }^{42}$ Pero estas aserciones ofrecen, como creo haber demostrado, unas coordenadas dentro de las cuales es posible entablar un diálogo filosófico de las religiones serio y pacífico para el cual la figura del mallorquín universal Ramon Llull es un punto de referencia obligado. Es más, estoy convencido que solamente ponderándolas desde una filosofía universal e integral en el sentido de Llull, puede rendirse justicia a las diferentes voces en el diálogo interreligioso, que cada una reclaman representar la verdad incondicional. La Teología pluralista de las religiones, en cambio, parece querer hacer un favor a todas estas voces al concederles a cada una de ellas una verdad relativa, pero, en realidad, no satisface con esto las exigencias de ninguna de ellas.

De esta suerte, la perspectiva inclusivista junto con la Filosofía de las religiones de Llull me parecen ser, por el momento, el camino más prometedor para llegar a una coexistencia pacífica de las diferentes religiones que Llull mismo invoca tan desesperadamente al principio

40 Joseph Ratzinger «Fe, verdad y cultura...», introd., citado por Eudaldo Forment, «Modelos de pensamiento y Filosofía cristiana a comienzos del tercer milenion, en: Tópicos. Revista de filosofia, 19 (2000), pp. 71-116, aquí p. 109.

41 Sobre las rationes necessariae puede consultarse ahora Jordi Pardo Pastor, «En torno a las rationes necessariae del conocimiento de Dios: De Santo Tomás de Aquino a Ramon Llull», en: Estudios Eclesiásticos 77 (2002), pp. 461-475.

42 Nostra aetate, núm. 2, traducimos de Karl Rahner y Herbert Vorgrimler, Kleines Konzilskompendium. Sämtliche Texte des Zweiten Vatikanums, Friburgo de Br., ${ }^{18} 1985$, p. 356: «La Iglesia católica no rechaza nada de lo que en estas religiones [es decir, Hinduismo, Budismo, Islam y Judaísmo] hay de verdadero y sagrado. Con gran respeto considera los estilos de vivir y de actuar que difieren en algunos casos de lo que ella misma cree verdadero y enseña, pero que, no pocas veces, dejan reconocer el rayo de luz que ilumina a todos los hombres. Sin embargo, incansablemente predica y debe predicar a Cristo, quien es 'el camino, la verdad y la vida' (Juan 14,6) en donde los hombres encuentran la plenitud de la vida religiosa y en donde Dios ha reconciliado a todos consigo mismo (véase II Cor $5,18 \mathrm{~s})$ ». 
de su Llibre del gentil e dels tres savis. ${ }^{43}$ Huelga decir que esta coexistencia pacífica de las religiones es una condición necesaria para uno de los mayores desafíos de la contemporaneidad: la paz entre los pueblos, aunque, como hay que advertir, no es ya su condición suficiente. ${ }^{44}$

Alexander Fidora FK/SFB 435-A2

J.W. Goethe-Universität D-60629 Frankfurt am Main a.fidora@em.uni-frankfurt.de

\section{APÉNDICE}

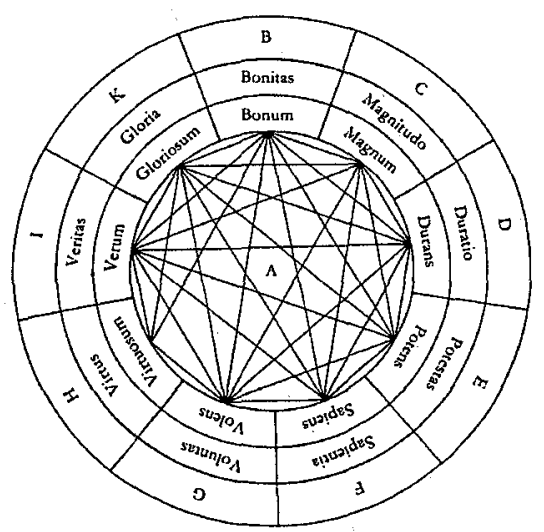

Figura A

43 Véase Ramon Llull, Llibre del gentil e dels tres savis, ed. Antoni Bonner, Palma, 1993, pp. 11-12: «A, con gran benahuyrança sserria aquesta, si per aquests arbres podiem esser en una lig e en una creenssa tots los homens qui som! E que la rancor ni la mala volentat no ffos en los homens qui ayren los uns los altres per desvariació e per contrarietat de creenses e de sectes. [...] Cogitans, senyors - dix lo savi a sos companyons-, quants son los dans qui·s seguexen com los homens no an una secta tan solament, ni quants son los bens que sserien si tuyt aviem una ffe, una lig».

44 Hans Küng ya viene insistiendo desde hace años en la importancia del diálogo interreligiso para la pacificación del mundo: «Kein Weltfrieden ohne Religionsfrieden», así su divisa (retomada nuevamente en su libro Weltethos fuir Weltpolitik und Weltwirtschaft, Munich, 1997, p. 160). No obstante, y como Küng mismo ha señalado, tampoco debe creerse que todos los conflictos bélicos de nuestros días son, en el fondo, conflictos culturales y/o religiosos, como insinúa Samuel P. Humtington, «The Clash of Civilizations?», en: Foreign Affairs, 72/3 (1993), pp. 22-49. 


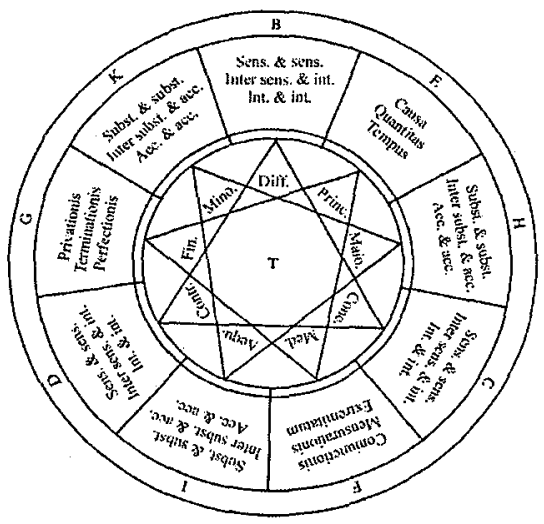

Figura $\mathrm{T}$

\begin{tabular}{|c|c|c|c|c|c|c|c|}
\hline BC & CD & DE & EF & FG & GH & HI & IK \\
\hline BD & CE & DF & EG & FH & GI & HK & \\
BE & CF & DG & EH & FI & GK & \\
BF & CG & DH & EI & FK & & \\
BG & CH & DI & EK & \multicolumn{2}{l}{} \\
BH & CI & DK & & \\
BI & CK & &
\end{tabular}

Tercera figura

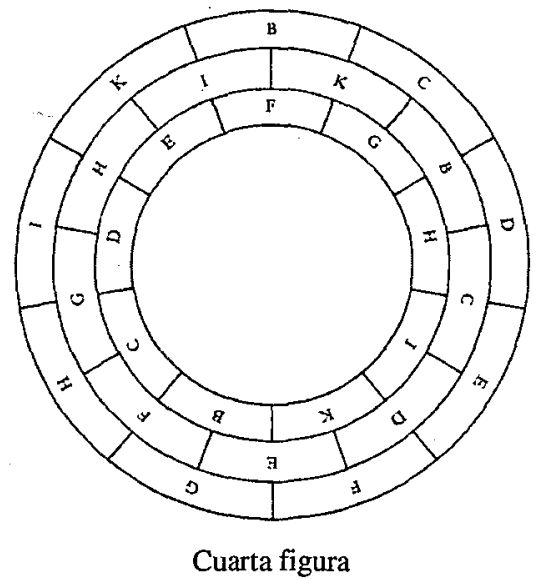

